\title{
Papers
}

\section{Medical prescription of heroin to treatment resistant heroin addicts: two randomised controlled trials}

\author{
Wim van den Brink, Vincent M Hendriks, Peter Blanken, Maarten W J Koeter, \\ Barbara J van Zwieten, Jan M van Ree
}

\begin{abstract}
Objective To determine whether supervised medical prescription of heroin can successfully treat addicts who do not sufficiently benefit from methadone maintenance treatment.

Design Two open label randomised controlled trials. Setting Methadone maintenance programmes in six cities in the Netherlands.

Participants 549 heroin addicts.

Interventions Inhalable heroin $(\mathrm{n}=375)$ or injectable heroin $(n=174)$ prescribed over 12 months. Heroin (maximum $1000 \mathrm{mg}$ per day) plus methadone (maximum $150 \mathrm{mg}$ per day) compared with methadone alone (maximum $150 \mathrm{mg}$ per day). Psychosocial treatment was offered throughout.

Main outcome measures Dichotomous, multidomain response index, including validated indicators of physical health, mental status, and social functioning. Results Adherence was excellent with 12 month outcome data available for $94 \%$ of the randomised participants. With intention to treat analysis, 12 month treatment with heroin plus methadone was significantly more effective than treatment with methadone alone in the trial of inhalable heroin (response rate $49.7 \%$ v 26.9\%; difference 22.8\%, 95\% confidence interval $11.0 \%$ to $34.6 \%$ ) and in the trial of injectable heroin (55.5\% v 31.2\%; difference 24.3\%, $9.6 \%$ to $39.0 \%$ ). Discontinuation of the coprescribed heroin resulted in a rapid deterioration in $82 \%$ $(94 / 115)$ of those who responded to the coprescribed heroin. The incidence of serious adverse events was similar across treatment conditions.

Conclusions Supervised coprescription of heroin is feasible, more effective, and probably as safe as methadone alone in reducing the many physical, mental, and social problems of treatment resistant heroin addicts.
\end{abstract}

\section{Introduction}

An estimated 25000 heroin addicts live in the Netherlands (population 16000000 inhabitants). ${ }^{1}$ Most users (75-90\%) inhale heroin ("chasing the dragon"). ${ }^{2}$ About three quarters of these addicts are served by a comprehensive treatment system, including various kinds of abstinence oriented treatment facilities and a wide range of facilities focusing on stabilisation or minimisation of harm. ${ }^{1}$ However, 5000-8000 people on methadone maintenance treatment regularly use illegal heroin, have serious physical and mental health problems, and live in socially marginalised conditions, characterised by illegal activities and a lack of social contacts outside the drug scene..$^{3-5}$

A large cohort study in Switzerland ascertained the feasibility, safety, and efficacy of medical prescription of injectable heroin to 1969 addicts. There were considerable improvements in physical and mental health, various aspects of social integration, and illegal drug use in 237 patients who completed 18 months of heroin treatment. $^{6}$ Although this study indicated that heroin assisted substitution treatment is feasible, the effectiveness of treatment was difficult to judge because no (random) controls were available, before and after comparisons were restricted to those who completed treatment, and participants were obliged to take part in mandatory psychosocial counselling and care. ${ }^{7-9}$ In a small randomised controlled trial $(n=51)$ in which intravenous heroin was compared with some standard treatment, functioning of the participants in the heroin group was significantly better after six months. ${ }^{10}$ However, these positive effects could have been the result of the additional, and mandatory, psychosocial interventions in the group allocated to heroin.

We examined the effectiveness of medically coprescribed heroine in two open label randomised controlled trials among heroin addicts who had responded insufficiently to methadone maintenance treatment.

\section{Methods \\ Design}

Five hundred and forty nine participants took part in two separate open label, multicentre $(n=6)$, randomised controlled (inhaling $\mathrm{n}=375$; injecting $\mathrm{n}=174$ ) and five treatment groups: three in the inhaling trial $(\mathrm{A}=\mathrm{control}$ group: 12 months of methadone alone; $\mathrm{B}=$ experimental group: 12 months of methadone plus heroin; $\mathrm{C}=$ comparison group: six months of methadone alone followed by six months of methadone plus heroin) and two in the injecting trial (group A and group B) (fig 1). At the end of the 12 months participants in the control groups were offered six months of medically prescribed methadone plus heroin. In all cases the medically prescribed heroin was discontinued for at least two
See also p 321

Central Committee on the Treatment of Heroin Addicts (CCBH), Stratenum, Universiteitsweg 100, 3584 CG Utrecht,

Netherlands

Wim van den Brink professor

Peter Blanken

researcher

Amsterdam

Institute for

Addiction Research,

Tafelbergweg 25,

1105 BC

Amsterdam,

Netherlands

Maarten W J Koeter assistant professor

Parnassia Addiction

Research Centre,

PO Box 2505 AA

The Hague,

Netherlands

Vincent M

Hendriks

senior researcher

Netherlands

Medicines

Evaluation Board,

Kalvermarkt 53 ,

The Hague,

Netherlands

Barbara J van

Zwieten

delegate to $C P M P$

Rudolf Magnus

Institute of

Neuroscience,

Utrecht University,

Utrecht,

Netherlands

Jan M van Ree

professor

Correspondence to:

W van den Brink

w.vandenbrink@

amc.uva.nl

bmj.com 2003;327:310 


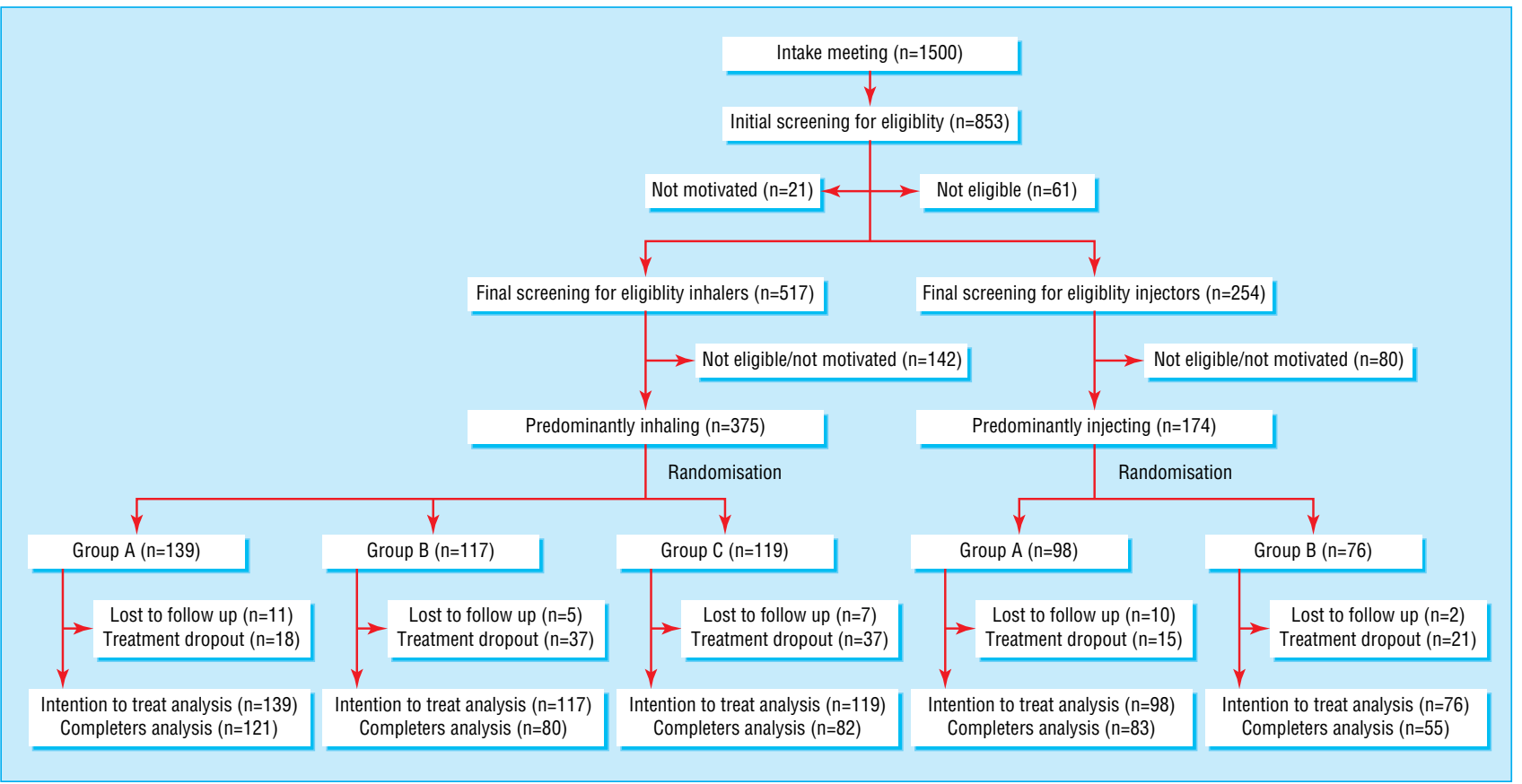

Fig 1 Progress of participants through stages of trials ( $A=$ control group—methadone only; $B=$ experimental group —methadone plus heroin; $C=c o m p a r i s o n$ group - methadone alone then methadone plus heroin)

months after the end of the experimental treatment period. All patients had full access to standard medical and psychosocial services.

An independent monitoring organisation centrally carried out randomisation separately for the two trials and the six cities and prestratified for sex and ethnicity. Because different attrition rates were expected in the different treatment conditions, participants within each block were randomised to the treatment conditions with a predetermined ratio of 135:115:125 for the control (A), experimental (B), and comparison (C) groups.

\section{Participants and treatments}

Included participants had regularly attended methadone maintenance programmes during the previous six months, were at least 25 years old, and met diagnostic criteria for heroin dependence during the past five years according to the Diagnostic and Statistical Manual of Mental Disorders, fourth edition (DSM-IV). ${ }^{11}$ They had all used at least $50 \mathrm{mg}$ (inhaling trial) or 60 $\mathrm{mg}$ (injecting trial) methadone a day for an uninterrupted period of at least four weeks in the previous five years; used illicit heroin daily or nearly every day; had poor physical or mental health or poor social functioning; and had not voluntarily abstained from heroin for longer than two months in the previous year. None of the women who took part were pregnant or breast feeding.

Participants were recruited from existing methadone maintenance programmes in six cities between 15 July 1998 and 1 October 2000. They were allocated to either the inhaling or the injecting trial depending on how they usually used the drug. Participants in the control groups were reallocated to their methadone programme of origin and received standard methadone maintenance treatment. Those in the experimental and comparison groups (group B for 12 months and group $\mathrm{C}$ for the last six months) were allowed to visit the newly established treatment units seven days a week, three times a day. Methadone was delivered once a day. Participants were allowed to use a maximum of $400 \mathrm{mg}$ heroin each visit and a maximum of $1000 \mathrm{mg}$ a day. They were not allowed to take any home. An aqueous solution of heroin hydrochloride was used in the injecting trial and a 3:1 mixture of heroin base and caffeine in the inhaling trial. Caffeine was added to increase the bioavailability of heroin to $35-45 \% .^{12}{ }^{13}$

\section{Assessments}

Independent research assistants assessed participants before the trial and then every two months. They assessed diagnosis and baseline characteristics using the composite international diagnostic interview (CIDI) and the European version of the addiction severity index (EuropASI). ${ }^{14-16}$

To be eligible for the study, participants had to be resistant to treatment as indicated by continued illegal use of opiates and poor physical functioning, mental health, and social integration. We defined poor physical functioning as score $\geq 8$ on the health symptoms scale of the Maudsley addiction profile (MAP-HSS), ${ }^{17}$ poor mental health as score $\geq 41$ in men and $\geq 60$ in women on the symptom checklist (SCL-90), ${ }^{18-20}$ and poor social integration as being involved in criminal activities for at least six days during the past month or at least six days without at least 30 minutes' personal contact a day with a non-using person. We validated self reported data on illicit cocaine against urinalysis (overall agreement $86 \% ; \kappa=0.66,95 \%$ confidence interval 0.58 to 0.75 ). Self reported data on charges by the police showed good agreement with data from the police register (overall agreement $90 \% ; \kappa=0.62,0.43$ to 0.82 ).

We used a prespecified dichotomous, multidomain outcome index as the primary outcome parameter. Patients were considered as responders if they showed at least $40 \%$ improvement in at least one of the three domains of inclusion (physical, mental, social) at the 
end of the treatment compared with baseline; if this improvement was not at the expense of a serious $(\geq 40 \%)$ deterioration in functioning in any of the other outcome domains; and if the improvement was not accompanied by a substantial $(\geq 20 \%)$ increase in use of cocaine or amphetamines.

Additional outcome parameters were completion of treatment and sustained response. We defined completion of treatment as the percentage of patients still in the intended treatment at the end of the trial. Sustained responders were participants who became a responder before the 12 month assessment and remained responders during the course of the trial. The effect of discontinuation was described in terms of the percentage of completers and responders who showed substantial deterioration ( $\geq 20 \%$ of baseline score) two months after discontinuation on at least one of the outcome domains on which they responded at 12 months.

The treating physician continuously documented all clinically significant adverse events and all serious and unexpected adverse events in the medical file and in the case record form at each assessment. ${ }^{21}$

\section{Statistical analysis}

To test the primary hypothesis we performed an intention to treat analysis separately for each trial and included all patients who were notified about the result of the randomisation. The magnitude of the difference between treatment conditions was calculated as a difference in the percentage of responders (RD). In addition, for the primary outcome variable we have provided an estimate of the number of people who would need to be treated to produce one additional responder $(\mathrm{NNT}=1 / \mathrm{RD})$. We used a multiple imputation procedure to estimate missing data for the 12 month assessment (Solas version 3.2; predictive model based method with five imputed datasets). Other analyses were performed with the same procedure. A clinically relevant effect was predefined as a percentage of responders of $20 \%$ or more. Based on two tailed testing with $\alpha=0.05$ and $\beta=0.20$ we estimated that we needed 108 participants per condition. Statistical analyses were performed with SAS version 8.0 (SAS Institute, Cary, NC).

Table 1 Baseline characteristics of 549 heroin addicts who participated in study, according to prescribed treatment

\begin{tabular}{|c|c|c|c|c|c|}
\hline & \multicolumn{3}{|c|}{ Inhaling } & \multicolumn{2}{|c|}{ Injecting } \\
\hline & $A^{*}(n=139)$ & $\mathrm{B}+(\mathrm{n}=117)$ & $C \ddagger(n=119)$ & $A^{*}(n=98)$ & $\mathrm{B}+(\mathrm{n}=76)$ \\
\hline Age (years) & 39.6 & 40.0 & 39.1 & 38.0 & 39.2 \\
\hline Male (\%) & 79.1 & 78.6 & 81.5 & 81.6 & 82.9 \\
\hline Ethnic Dutch (\%) & 82.7 & 80.2 & 80.5 & 94.9 & 96.1 \\
\hline Employed (\%) & 6.5 & 5.2 & 12.1 & 8.2 & 8.1 \\
\hline Stable housing (\%) & 90.6 & 89.7 & 86.4 & 84.7 & 77.6 \\
\hline \multicolumn{6}{|l|}{ Regular drug use (years): } \\
\hline Heroin & 16.7 & 16.9 & 16.4 & 15.4 & 16.6 \\
\hline Methadone & 12.4 & 12.9 & 11.9 & 11.7 & 12.6 \\
\hline Cocaine & 8.0 & 9.3 & 7.8 & 10.1 & 9.6 \\
\hline Amphetamines & 1.5 & 1.4 & 1.8 & 3.0 & 3.1 \\
\hline \multicolumn{6}{|l|}{ Drug use in past month (days): } \\
\hline Heroin & 25.9 & 25.9 & 25.5 & 25.9 & 25.2 \\
\hline Methadone & 28.7 & 28.9 & 29.1 & 29.1 & 29.1 \\
\hline Cocaine & 15.2 & 15.2 & 13.4 & 18.0 & 15.5 \\
\hline Amphetamines & 0.1 & 0.1 & 0.7 & 1.2 & 0.9 \\
\hline Previous drug free treatment (\%) & 59.4 & 54.7 & 58.8 & 67.0 & 65.8 \\
\hline Ever overdosed (\%) & 30.9 & 28.2 & 29.4 & 49.0 & 47.4 \\
\hline Additional need for addiction treatment (\%)§ & 66.9 & 65.8 & 72.9 & 63.3 & 57.9 \\
\hline \multicolumn{6}{|l|}{ Physical health: } \\
\hline Mean MAP-HSS & 11.6 & 10.6 & 11.8 & 11.1 & 12.1 \\
\hline HIV positive (\%) & 9.9 & 3.9 & 5.6 & 13.3 & 13.3 \\
\hline Somatic medication (\%) & 28.8 & 21.4 & 24.4 & 22.5 & 19.7 \\
\hline Additional need for somatic treatment (\%)§ & 29.2 & 24.8 & 36.4 & 39.8 & 35.5 \\
\hline \multicolumn{6}{|l|}{ Mental health: } \\
\hline Mean SCL-90 & 70.7 & 68.4 & 79.4 & 72.7 & 76.3 \\
\hline Ever attempted suicide (\%) & 17.3 & 25.6 & 26.9 & 40.2 & 35.5 \\
\hline Psychiatric medication (\%) & 33.1 & 32.5 & 38.7 & 35.7 & 34.7 \\
\hline Any current DSM-IV diagnosis (\%) & 27.7 & 28.2 & 36.1 & 34.0 & 31.6 \\
\hline Additional need for psychiatric treatment (\%)§ & 26.6 & 26.5 & 31.9 & 32.7 & 39.6 \\
\hline \multicolumn{6}{|l|}{ Social functioning: } \\
\hline Illegal activities in past month (days) & 11.2 & 11.4 & 8.4 & 11.5 & 12.9 \\
\hline Contact with non-users in past month (days) & 16.3 & 15.8 & 14.1 & 13.7 & 12.1 \\
\hline Median No of charges for theft & 10.0 & 6.0 & 8.0 & 10.0 & 15.0 \\
\hline Median time incarcerated (months) & 12.0 & 12.0 & 10.0 & 19.0 & 13.0 \\
\hline
\end{tabular}

MAP-HSS=Maudsley addiction profile-health symptoms score ${ }^{17}$; SCL-90=symptom checklist-90 item version ${ }^{18-20}$; DSM-IV=Diagnostic and Statistical Manual of Mental Disorders, fourth edition.

*12 months of methadone alone.

t12 months of methadone plus heroin.

6 months of methadone alone, followed by 6 months of methadone plus heroin

$\S$ Based on ASI severity rating $\geq 5$ 


\section{Results}

Table 1 shows details of the participants recruited. There were no significant differences between the groups.

Twelve month follow up data were available for $93-94 \%$ of the randomised participants (fig 1). Completion rates were high in all treatment groups, but somewhat higher in the group allocated to methadone alone than in the group allocated to heroin plus methadone (table 2). However, 7\% (13) of the intention to treat population in the experimental condition never started the heroin treatment, and $6 \%$ (11) were expelled from heroin treatment because of (repeated) violation of the house rules. On average, participants who completed treatment visited the heroin dispensing units 2.1 times a day, used $260 \mathrm{mg}$ heroin a visit, and used $548 \mathrm{mg}$ a day. The mean dose of methadone ranged from $67 \mathrm{mg}$ a day in the inhaling protocol to 71 $\mathrm{mg}$ a day in the injecting protocol in the control groups and from $57 \mathrm{mg}$ to $60 \mathrm{mg}$ a day in the experimental and comparison groups.

The experimental treatment with 12 months of methadone plus heroin was significantly more effective than 12 months of methadone alone, both in the inhaling trial (difference $=22.8 \%, 95 \%$ confidence interval $11.0 \%$ to $34.6 \%$; number needed to treat $=$ $4.4,2.9$ to 9.1 ) and in the injecting trial (difference $=$ $24.3 \%, 9.6 \%$ to $39.0 \%$; number needed to treat $=4.1$, 2.6 to 10.4) (table 2). Treatment centre and the interaction between centre and condition were not significantly related to outcome. Similar effects were observed for the participants treated for six months (data not presented).

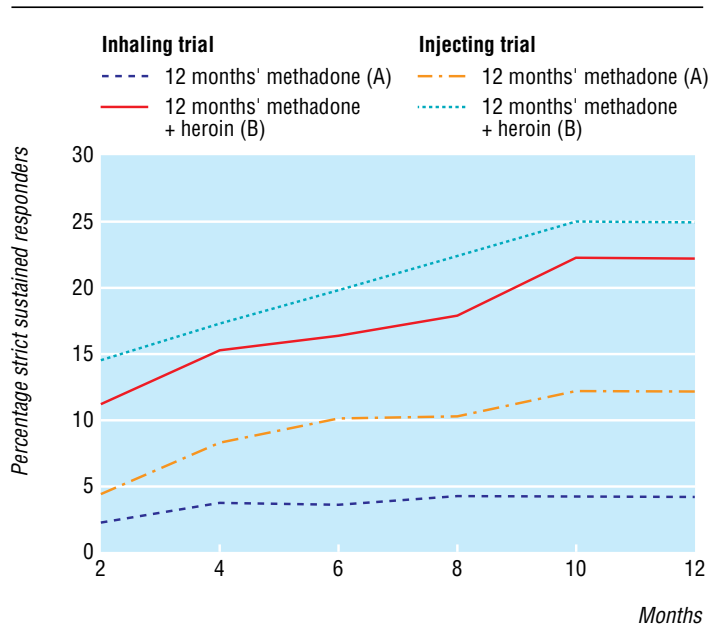

Fig 2 Sustained response to treatment during 12 months of trials of prescribed heroin (inhaling and injecting)

Results for those who completed the study were similar to those from the intention to treat analysis (table 2). Sustained response rates were of course lower than simple response rates, but the difference between the treatment conditions remained significant (table 2). The difference in the rate of sustained response increased during the course of the study (fig 2).

Treatment responders showed clinically relevant improvements in all outcome domains. These changes were absent in non-responders, with the exception of a reduction in illegal activities in the participants who received heroin in addition to methadone

Table 2 Selected outcome measures in heroin addicts according to prescribed treatment. Figures are numbers (percentage) of participants

\begin{tabular}{|c|c|c|c|c|c|c|}
\hline & \multicolumn{3}{|c|}{ Inhaling } & \multicolumn{3}{|c|}{ Injecting } \\
\hline & $A^{*}(n=139)$ & $B+(n=117)$ & Difference $\neq(95 \% \mathrm{Cl})$ & $A^{*}(n=98)$ & $B+(n=76)$ & Difference (B-A) $(95 \% \mathrm{Cl})$ \\
\hline $\begin{array}{l}\text { Completed } 12 \text { months' } \\
\text { treatment }(\%)\end{array}$ & $121(87)$ & $80(68)$ & 18.7 (8.8 to 28.6$)$ & $83(85)$ & $55(72)$ & 12.3 (0.2 to 24.5$)$ \\
\hline \multicolumn{7}{|l|}{ Response at 12 months' (\%): } \\
\hline ITT/MI & $37(27)$ & $58(50)$ & 22.8 (11.0 to 34.6$)$ & $31(31)$ & $42(56)$ & 24.3 (9.6 to 39.0$)$ \\
\hline $\mathrm{CA} / \mathrm{MI}$ & $34(28)$ & $41(51)$ & 23.5 (9.8 to 37.2$)$ & $32(39)$ & $32(58)$ & 19.4 (2.5 to 36.3$)$ \\
\hline $\begin{array}{c}\text { Sustained response at } 12 \\
\text { months (\%) (ITT/MI) }\end{array}$ & $6(4)$ & $26(22)$ & 17.9 (9.7 to 26.1$)$ & $11(12)$ & $19(25)$ & 13.1 (1.5 to 24.7 ) \\
\hline
\end{tabular}

ITT=intention to treat (all patients who were notified about result of randomisation); Ml=multiple imputation for missing values; CA=completers' analysis.

*12 months of methadone alone.

12 months of methadone plus heroin.

Table 3 Mean changes in status in participants allocated to methadone plus heroin who deteriorated in the two months after discontinuation of heroin treatment

\begin{tabular}{|c|c|c|c|c|c|c|}
\hline & \multicolumn{3}{|c|}{ Inhaling ( $\mathrm{n}=34$ ) } & \multicolumn{3}{|c|}{ Injecting ( $\mathrm{n}=27)$} \\
\hline & Baseline & Month 12 & Month 14 & Baseline & Month 12 & Month 14 \\
\hline MAP-HSS (score range 0-40) & 10.9 & 5.4 & 13.0 & 12.0 & 4.3 & 13.2 \\
\hline SCL-90 (score range $0-360$ ) & 70.0 & 22.3 & 75.6 & 74.2 & 30.6 & 62.1 \\
\hline $\begin{array}{l}\text { Days of illegal activities (range } \\
0-30 \text { days) }\end{array}$ & 11.1 & 0.4 & 15.7 & 13.5 & 0.3 & 16.0 \\
\hline $\begin{array}{l}\text { Days with no personal contact } \\
\text { (range } 0-30 \text { days) })^{\star}\end{array}$ & 15.2 & 11.2 & 21.2 & 17.3 & 11.9 & 19.5 \\
\hline $\begin{array}{l}\text { Days of cocaine use (range 0-30 } \\
\text { days) }{ }^{\star}\end{array}$ & 11.5 & 8.6 & 11.3 & 12.6 & 8.1 & 12.8 \\
\hline $\begin{array}{l}\text { Days in controlled environment } \\
\text { (range } 0-30 \text { days) } \dagger\end{array}$ & - & 0 & 0.1 & - & 0.1 & 0.1 \\
\hline
\end{tabular}

MAP-HSS=Maudsley addiction profile-health symptoms score; SCL-90=symptom checklist-90 item version.

*Days in past month without at least 30 minutes' personal contact per day with people not using heroin.

†No baseline data presented because participants who spent $>7$ days in controlled environment excluded from baseline assessment. 
Table 4 Serious adverse events in intention to treat population during 12 month study period

\begin{tabular}{|c|c|c|c|c|c|c|c|c|}
\hline & \multicolumn{4}{|c|}{ Inhaling ( $n=375)$} & \multicolumn{3}{|c|}{ Injecting (n=174) } & \multirow[b]{2}{*}{ Total $(n=549)$} \\
\hline & $A(n=139)$ & $B(n=117)$ & $C(n=119)$ & Subtotal & $A(n=98)$ & B $(n=76)$ & Subtotal & \\
\hline No of events & 14 & 14 & 12 & 40 & 7 & 11 & 18 & 58 \\
\hline No (\%) with $\geq 1$ event & $11(7.9)$ & $14(12.0)$ & $11(9.2)$ & $36(9.6)$ & $7(7.1)$ & $9(11.8)$ & $16(9.2)$ & $52(9.5)$ \\
\hline $\begin{array}{l}\text { Possibly related to heroin } \\
\text { use }\end{array}$ & NA & 5 & 1 & 6 & NA & 4 & 4 & 10 \\
\hline $\begin{array}{l}\text { Probably/definitely related to } \\
\text { heroin use }\end{array}$ & NA & 2 & 0 & 2 & NA & 0 & 0 & 2 \\
\hline
\end{tabular}

$\mathrm{NA}=$ not applicable as heroin not prescribed in control group.

Many $(82 \%, 94)$ of the treatment responders in the experimental group deteriorated substantially in the two months after the planned discontinuation of the coprescribed heroin. Two months after discontinuation the mean scores on the constituent scales of the multidomain outcome index had returned to the scores seen just before the start of the intervention (table 3).

Table 4 shows that the incidence of serious adverse events (almost $10 \%$ of the intention to treat population) was similar in all groups. Only two events were probably or definitely related to the study medication: one serious (but not fatal) heroin overdose and one non-fatal car crash in someone using heroin and cocaine. There were three deaths (one in group $\mathrm{A}$, one in group $\mathrm{B}$, and one in group $\mathrm{C}$ (in the first phase before heroin was prescribed)), one of which was probably related to the coprescribed heroin.

\section{Discussion}

In our two trials supervised medical coprescription of heroin to treatment resistant heroin addicts was more effective than and probably just as safe as methadone alone. We saw considerable improvements in physical and mental condition and social functioning and few serious adverse events. The observed positive effects were not dependent on the route of administration of the coprescribed heroin. Our results also indicate that medical coprescription of heroin should be long lasting to obtain stable positive outcomes. However, depending which response criterion we used, 45-88\% of the participants did not respond to the medical coprescription of heroin, and additional interventions must be developed and implemented.

Our findings generally agree with those from the small randomised controlled trial of Perneger et $\mathrm{al}^{10}$ and those from the large uncontrolled study of Rehm et al. $^{6}$ The most important advantage of our study is that the observed effects of the coprescription of heroin could not be attributed to a difference in the offer of psychosocial treatment between the experimental and the control groups.

\section{Limitations}

There were, however, some methodological limitations. Given the nature of the medication under study we could not use a double blind design. ${ }^{22}$ We also exclusively used self reported outcome data. However, research has shown that self reported data collected by researchers is generally truthful, reliable, and valid in this kind of population, provided that confidentiality is ensured and that no sanctions are connected to the content of the answers. ${ }^{23}$ Our study met these criteria. In addition, the self reported data on police charges and use of cocaine corresponded well with data from

\section{What is already known on this topic}

Methadone maintenance is used to treat heroin addicts, though a substantial number do not experience any benefit

A few restricted studies have shown that the medical prescription of heroin in combination with mandatory psychosocial treatments may be feasible

\section{What this study adds}

Supervised medical prescription of a combination of methadone plus heroin is feasible, safe, and effective with clinically relevant improvements in physical health, mental status, and social functioning (including substantial reductions in criminal behaviours)

the police register and from urinalysis. Finally, there was a difference in settings between the treatment groups. Methadone prescription and dispensing took place in existing treatment locations with existing treatment staff, whereas the combined prescription of methadone and heroin took place in newly established locations with specially recruited staff members. Despite these limitations, however, we consider that our study provides strong evidence of the efficacy of prescribed heroin for addicts who are resistant to other forms of treatment.

We thank Ineke Huijsman for her coordinating activities during the trials. The Netherlands Medicines Evaluation Board was not involved in the study.

Contributors: All authors were responsible for analysis and interpretation, revising the manuscript, and final approval of the paper. WvdB and VMH were also responsible for concept and design and the first draft. BJvZ and JMvR were also responsible for concept and design. WvdB is guarantor.

Funding: The study was commissioned and financially supported by the Netherlands Ministry of Health, Welfare and Sports. The guarantor accepts full responsibility for the conduct of the study, had access to the data, and controlled the decision to publish.

Competing interests: None declared.

Ethical approval: The study was approved by the Central Committee on Medical Ethics (KEMO) and conducted according to ICH/EU Good Clinical Practice guidelines. ${ }^{21}$ All participants provided written informed consent.

1 Van den Brink W, Hendriks VM, Van Ree J. Medical co-prescription of heroin to chronic, treatment-resistant methadone patients in the Netherlands. J Drug Issues 1999;29:587-608.

2 Nationale Drug Monitor (NDM). Jaarbericht NDM 2001. Utrecht: Bureau NDM, 2001.

3 Driessen FMHM. Methadonverstrekking in Nederland. Utrecht: Bureau Driessen, 1990.

4 Driessen FMHM. Methadoncliënten in Nederland. Utrecht: Bureau Driessen, 1992. 
5 Driessen FMHM, Völker BGM, Kregting J, Van der Lelij B. De ontwikkeling van de situatie van methadoncliënten gedurende twee jaar. Utrecht: Bureau Driessen, 1999.

6 Rehm J, Gschwend P, Steffen T, Gutzwiller F, Dobler-Mikola A, Uchtenhagen A. Feasibility, safety, and efficacy of injectable heroin prescription for refractory opioid addicts: a follow-up study. Lancet 2001;358:1417-20.

7 Farrel M, Hall W. The Swiss heroin trials: testing alternative approaches. BMJ 1998;316:639.

8 Wodak A. Prescribing heroin: nothing else to fear but fear itself? Illicit drug policy based on punitive measures has failed, and it is time to seek a health care approach. Med J Austr 1998;168:590-1.

9 Ali R, Auriacombe M, Casas M, Cottler L, Farrel M, Kleiber D, et al. Report of the external panel on the evaluation of the swiss scientific studies of medically prescribed narcotics to drug addicts. Sucht 1999;45:160-70.

10 Perneger TV, Giner F, Del Rio M, Mino A. Randomized trial of heroin maintenance programme for addicts who fail in conventional drug treatments. BMJ 1998;317:13-8.

11 American Psychiatric Association. Diagnostic and statistical manual of mental disorders. 4th ed. Washington DC: American Psychiatric Association, 1994

12 Huizer H. Analytical studies on illicit heroin. V. Efficacy of volatilization during heroin smoking. Pharmaceutisch Weekblad 1987;9:203-11.

13 Hendriks VM, Van den Brink W, Blanken P, Bosman I, Van Ree JM. Heroin self-administration by means of 'chasing the dragon': pharmacodynamics and bio-availability of inhaled heroin. Eur Neuropsychopharmacol 2001;11:241-52.

14 Kokkevi A, Hartgers C. EuropASI: European adaptation of a multidimensional assessment instrument for drug and alcohol dependence. Eur Addict Res 1995;1:208-10
15 McLellan AT, Luborsky L, Cacciola J, Griffith J, McGahan P, O'Brien CP. Guide to the addiction severity index: background, administration, and field testing results. Rockville MD: National Institute on Drug Abuse, 1985.

16 Robins LN, Wing J, Wittchen HU. The composite international diagnostic interview: an epidemiologic instrument suitable for use in conjunction with different diagnostic systems and in different cultures. Arch Gen Psychiatry 1988;45:1069-77.

17 Marsden J, Gossop M, Stewart D, Best D, Farrell M, Lehmann P, et al. The Maudsley addiction profile (MAP): a brief instrument for assessing treatment outcome. Addiction 1998;93:1857-67.

18 Derogatis LR. SCL-90-R: administration, scoring and procedures. Manual II. Towsen MD: Clinical Psychometric Research, 1983.

19 Hendriks VM. Psychiatric disorders in a Dutch addict population: rates and correlates of DSM-III diagnosis. J Consult Clin Psychol 1990;58:158-65.

20 Franken IHA, Hendriks VM. Screening and diagnosis of anxiety and mood disorders in substance abuse patients. Am J Addict 2001;10:30-9.

21 ICH Steering Committee. International conference on harmonisation of technical requirements for registration of pharmaceuticals for human use: statistical principles for clinical trials: note for guidance on statistical principles for clinical trials. London: European Agency for Evaluation of Medicinal Products, Human Medicines Evaluation Unit, 1998 (CPMH/ICG/33/95).

22 Bammer G, Dobler-Mikola A, Fleming PM, Strang J, Uchtenhagen A. Prescription heroin to dependent users: integrating science and politics. Science 1999;284:1277-8

23 Rounsaville BJ. Rationale and guidelines for using comparable measures to evaluate substance abusers: an overview. In: Rounsaville BJ, Tims FM, Horton AM, Sowder BJ, eds. Diagnostic source book on drug abuse research and treatment. Rockville, MD: US Department of Health and Human and treatment. Rock

(Accepted 23 May 2003) 